\title{
Incidence of gastroenteropancreatic neuroendocrine tumours: a systematic review of the literature
}

\author{
M Fraenkel", M Kim ${ }^{1, *}$, A Faggiano ${ }^{2,3}$, W W de Herder ${ }^{4}$, G D Valk ${ }^{5}$ and On behalf of the \\ Knowledge NETwork
}

Endocrinology, Soroka University Medical Center and the Faculty of Health Sciences, Ben-Gurion University of the Negev, Beer Sheeba, Israel

${ }^{1}$ Mount Sinai Medical Center, New York, New York, USA

${ }^{2}$ Department of Clinical Medicine and Surgery, University Federico II, Naples, Italy

${ }^{3}$ Endocrinology, National Cancer Institute, Fondazione G. Pascale, Naples, Italy

${ }^{4}$ Erasmus MC, Rotterdam, The Netherlands

${ }^{5}$ Department of Internal Medicine, Division of Gastroenterology, University Medical Center Utrecht, Utrecht,

The Netherlands

*(M Fraenkel and M Kim contributed equally to this work)

Correspondence

should be addressed

to M Fraenkel

Email

meravfra@gmail.com

\begin{abstract}
Based on the current medical literature, the worldwide incidence of neuroendocrine tumours (NETs) seems to have increased; however, a systematic literature overview is lacking. This study aimed to collect all available data on the incidence of gastroenteropancreatic (GEP)NETs and characteristics of population to establish their epidemiology. A sensitive MEDLINE search was carried out. The papers were selected via a cascade process that restricted the initial pool of 7991 articles to 33, using predefined inclusion and exclusion criteria. Original articles evaluating the incidence of sporadic GEP-NETs in regional, institutional and national registries were considered. The majority of data originated from the US National Cancer Institute Surveillance, Epidemiology and End Results database and from national cancer registries in Western Europe. Generally, because of the retrospective nature of existing databases the outcomes of studies might be biased, which hinders the drawing of firm conclusions. The age-adjusted incidence of GEP-NETs has increased steadily over the past four decades (1973-2007), increasing 3.65-fold in the USA and 3.8- to 4.8-fold in the UK. Incidence has changed variably from one anatomical site to another. The greatest increase in incidence occurred for gastric and rectal NETs, while the smallest increase occurred for small intestine NETs. There were gender and racial differences, which differed site by site and, in some cases, changed over time. The incidence rates (IRs) of GEP-NETs have increased significantly in the last 40 years. Data are only available from North America, Western Europe and Japan. A siteby-site analysis revealed that the IRs of some NETs increased more than those of others.
\end{abstract}

\author{
Key Words \\ - neuroendocrine tumours \\ - carcinoids \\ - epidemiology \\ - incidence
}

Endocrine-Related Cancer (2014) 21, R153-R163

\section{Introduction}

Neuroendocrine tumours (NETs) are heterogeneous neoplasms arising from different cells distributed in many organs and tissues that share a common neuroendocrine phenotype. NETs have been recognized as biologically different from classical carcinomas since the first description of a 'karzinoid' by Oberndorfer at the http://erc.endocrinology-journals.org DOI: $10.1530 /$ ERC-13-0125
(C) 2014 Society for Endocrinology Printed in Great Britain
Published by Bioscientifica Ltd 
beginning of the twentieth century (Oberndorfer 1907). However, only in recent years have well-defined histological and immunohistochemical criteria allowed clinicians to reliably identify NETs and differentiate them from other types of tumours. The World Health Organization (WHO) classification criteria of NETs, which have been revised recently by an international pathological board, are basic instruments that have superseded all previous NET classifications and terms, such as APUDoma, argentaffinoma and carcinoid (Klimstra et al. 2010a,b, Klöppel et al. 2010).

The most recent 2010 WHO system renders all NETs as neoplasms with a malignant potential and the acronym NEN is recommended corresponding to the term neuroendocrine neoplasia (Klimstra et al. 2010a,b, Klöppel 2011).

Nowadays, more and more NETs are being diagnosed in surgical samples or biopsy, in the absence of a classical clinical picture suggestive of NETs. Furthermore, highly sensitive and specific imaging techniques, such as computed tomography (CT), SPECT with ${ }^{111}$ In-pentetreotide and positron emission tomography with ${ }^{68} \mathrm{Ga}$-DOTATATE, ${ }^{11} \mathrm{C}$ 5-HTP and ${ }^{18} \mathrm{~F}$-DOPA, multidetector-row CT, endoscopic ultrasound and video capsule endoscopy, are now available to help detect and localize symptomatic and asymptomatic NETs (Kwekkeboom et al. 2009, Sundin et al. 2009).

Despite several recent articles from monocentric and multicentric national studies being published, we still lack adequate epidemiological information on NETs. This lack of data only partially explains the strong discrepancy between the estimated incidence of gastroenteropancreatic (GEP)-NETs and the higher frequency of these tumours found in autopsy series (Berge \& Linell 1976).

The aim of this study was to carry out a systematic literature review to collect all available data on the worldwide epidemiology, and specifically incidence, of GEP-NETs and to identify potential trends in the incidence rates (IRs) of these tumours.

\section{Materials and methods}

Prospective and retrospective epidemiological studies that evaluated the incidence and/or prevalence of GEP-NETs in people at any age were considered. Studies were included if they reported the incidence and/or prevalence of GEP-NETs. Autopsy series were excluded. Only original articles were included; review articles and abstracts were excluded. Studies on patients with multiple endocrine neoplasia (MEN1) and other familial NETs were excluded.
A search strategy that included search terms on study design, patient group, clinical problem and outcome of interest was implemented using the MEDLINE database (1966-07/2011). Search terms were 'Incidence'(Mesh) OR 'Data Collection'(Mesh)) OR 'Prevalence'(Mesh)) AND (('Neuroendocrine Tumors'(Mesh) OR 'Carcinoma, Neuroendocrine'(Mesh) OR 'Gastro-enteropancreatic neuroendocrine tumor' (Supplementary Concept)) OR ((neuroendocrine AND (tumors OR tumour)) OR (neuro-endocrine AND (tumors OR tumour)) OR (neuro endocrine AND (tumors OR tumour) ) OR (neuroendocrine carcinoma) OR (neuro-endocrine carcinoma) OR (neuro endocrine carcinoma) OR (gastro entero pancreatic neuroendocrine tumors) OR (GEP neuroendocrine tumor) OR (gastro entero pancreatic NETs) OR (GEP NETs) OR (gep tumor) OR (gep tumour) OR (gep net) OR (gep neuroendocrine tumor) OR (gep NETs) OR carcinoid* OR insulinoma* OR gastrinoma* $^{*}$

There were no language restrictions. Studies reporting on regional, institutional and national registries were included if they reported annual IRs. The bibliographies of all the retrieved and relevant publications identified by the search were investigated for further relevant studies. All the identified references were assessed by title and abstract to determine possible eligibility; i.e. whether these met the inclusion criteria: concerning patient group: patients with GEP-NETs and outcomes reported: incidence and/or prevalence and type of registry (i.e. national, regional or institutional). Full-paper copies of the subsequent identified articles were retrieved, and each was assessed for eligibility using pre-defined data extraction sheets. Studies were excluded if they reported IRs of all NETs with no specific data on GEP-NETs separately. Each paper included was further assessed and information was extracted using standard data extraction sheets. Data on the country or region, type of registry, patient identification procedure, patient population (location of primary tumour and type of tumour), reported time period and outcomes (incidence and/or prevalence figures) were collected. In case of doubt, the papers were discussed in teams of at least two reviewers and a consensus was reached.

Particularly in the USA where the Surveillance, Epidemiology and End Results (SEER) database is publicly available, different groups had used the same data and reported similar IRs over similar time periods. In the majority of cases, we included all papers as the studies reported the incidence of NETs using different inclusion criteria or reported it in different ways (e.g. annually vs 5 -year incidence). When the same group published updated data in the same way, the reports were grouped

Published by Bioscientifica Ltd. 
together. Extracted data are summarized in evidence tables on a study-by-study narrative basis (for full data tables, see the Supplementary appendix, see section on supplementary data given at the end of this article). Because of the heterogeneity of study design, registry type, follow-up and outcomes, no attempt was made to pool the results. The evidence tables were compiled following collective discussion by the working party. IRs were reported as the number of cases per 100000 persons in the population studied per year (unless otherwise stated). In cases where age-adjusted IRs were reported, these values were used.

\section{Results}

Of the 7991 publications that came up in the initial search, 199 papers were judged to be potentially eligible based on their title and abstract and were reassessed on a full-text basis. A total of 33 papers fulfilled all the specified inclusion and exclusion criteria. These publications covered the IRs of GEP-NETs at different time periods between the years 1958 and 2007 in different parts of the world (Fig. 1). None of the reports included data on the prevalence of GEP-NETs by anatomical location in the gastrointestinal (GI) tract. Yao et al. (2008) reported an estimated 29-year limited-duration prevalence of NETs on 1 January 2004 in the USA of 103312 cases or 35/100 000 . Reports on the IRs of GEP-NETs were mainly from North
America and Western Europe with one report being from Japan (also reporting prevalence rates) (Fig. 1). The majority of data from North America originated from the US SEER database. Incidence was usually reported as annual age-adjusted incidence per 100000 population. In some cases, incidence was reported separately for males and females and by race; in others, incidence was reported for the whole population without separating the genders or race.

The methods of patient identification for national and regional registries included in this review are listed in Table 1.

\section{Data from the USA}

Numerous cancer registries exist in the USA on national, state and institutional levels. The majority of, and most robust, epidemiological studies have been carried out using the national registries. The End Results Group included cancer cases from 1950 to 1969. The Third National Cancer Survey was a more short-lived registry including patients from 1969 to 1971 . More recently, the most prominent studies have been carried out using the SEER cancer registry. The most up-to-date SEER data represent $\sim 28 \%$ of the population of the USA and includes information on 7262696 cancer patients diagnosed from 1973 to 2009 . The SEER database is considered

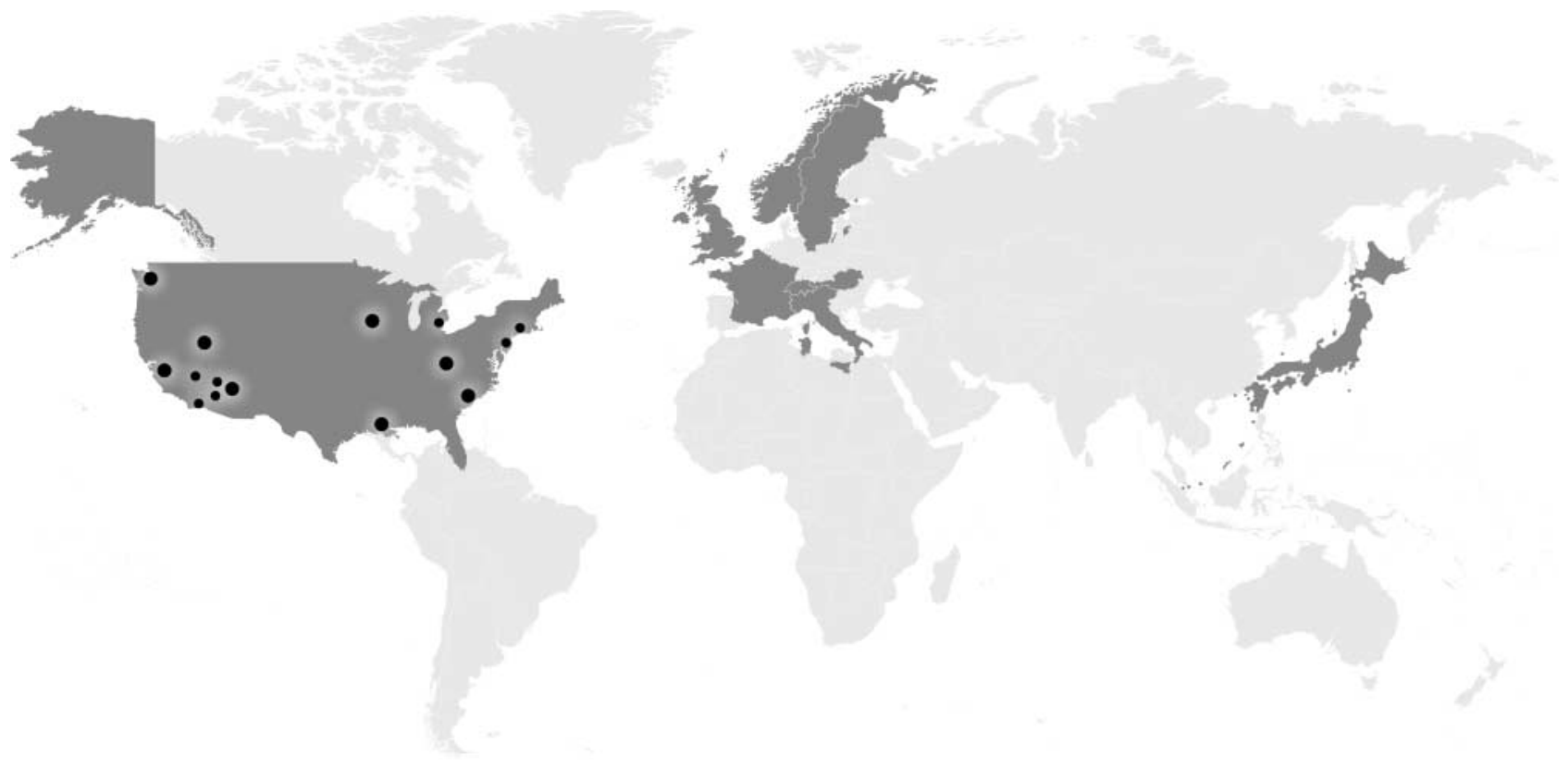

Figure 1

Map of the world with representation of countries contributing data for the review in dark grey. Centres contributing the most recent SEER registry data are marked within the USA.

http://erc.endocrinology-journals.org DOI: 10.1530/ERC-13-0125
(C) 2014 Society for Endocrinology Printed in Great Britain
Published by Bioscientifica Ltd 
Table 1 Method employed by each country for the identification of NET patients for national/regional registry

\begin{tabular}{|c|c|c|}
\hline Country & $\begin{array}{l}\text { Method of patient identification for } \\
\text { national/regional registry }\end{array}$ & Reference \\
\hline USA (SEER database) ${ }^{a}$ & Various editions of the ICD-O codes & $\begin{array}{l}\text { Chow et al. (1996), Severson et al. (1996), Modlin \& } \\
\text { Sandor (1997), Crocetti \& Paci (2003), Modlin } \\
\text { et al. (2003, 2007), Maggard et al. (2004), } \\
\text { Hodgson et al. (2005), Yao et al. (2007, 2008), } \\
\text { Gustafsson et al. (2008), Halfdanarson et al. } \\
\text { (2008), Hauso et al. (2008), Bilimoria et al. (2009), } \\
\text { and Lawrence et al. (2011) }\end{array}$ \\
\hline Norway & $\begin{array}{l}\text { Physicians and pathology departments reporting } \\
\text { to national registry with check by the } \\
\text { Norwegian registry of cancer }\end{array}$ & Hauso et al. (2008) \\
\hline UK & Regional registries based on ICD-O codes & Ellis et al. (2010) \\
\hline Switzerland (Vaud) & $\begin{array}{l}\text { Voluntary agreement between recording medical } \\
\text { institutions and the registry. Unclear how } \\
\text { patients are identified }\end{array}$ & Levi et al. (1993, 2000) \\
\hline Sweden & National registry based on the ICD-7 codes & Hemminki \& Li (2001) and Landerholm et al. (2010) \\
\hline Italy (Tuscany) & Regional cancer registry based on the ICD-O codes & Crocetti et al. (1997) and Caldarella et al. (2011) \\
\hline Austria & $\begin{array}{l}\text { Registry based on reports from } 40 \text { of the } 41 \\
\text { pathology departments }\end{array}$ & Niederle et al. (2010) \\
\hline France (Burgundy) & $\begin{array}{l}\text { Data collected by cancer registry staff using } \\
\text { multiple databases: pathology laboratories, } \\
\text { university hospitals, local hospitals, private } \\
\text { surgeons, oncologists, gastroenterologists, } \\
\text { general practitioners, and monthly reviews of } \\
\text { death certificates }\end{array}$ & Lepage et al. $(2004,2006)$ \\
\hline Japan & $\begin{array}{l}\text { Questionnaire to heads of departments about the } \\
\text { number of patients with GEP-NET }\end{array}$ & Ito et al. (2010) \\
\hline
\end{tabular}

ICD-O, International Classification of Diseases for Oncology.

aSurveillance, Epidemiology and End Results.

to be roughly representative of the US population with respect to features such as socio-economic status, education, and urban/rural residence (seer.cancer.gov website).

\section{Data from outside the USA}

In Europe, data on the incidence of GEP-NETs, separated by anatomical location, arise from the national and regional registries. The countries in Europe for which IRs were reported specifically for GEP-NETs (fulfilling our inclusion criteria) were the UK, Sweden, Norway, France, Switzerland, Austria and Italy. In some of the countries, IRs were published several times for different time periods, allowing some insights into trends in the incidence of GEP-NETs (the UK, France, Switzerland, Norway and Sweden). Some countries reported large series of GEPNET patients but were not population based and therefore could not report on annual IRs (Li et al. 2008, Younes 2008, Lombard-Bohas et al. 2009, Ploeckinger et al. 2009, Garcia-Carbonero et al. 2010). Some registries reported the IRs of all GEP-NETs or all NETs, including lung NETs, and not site-specific IRs (Scotland, The Netherlands, Denmark and early reports from England and Ireland), and were therefore not included in this review (Buchanan et al. 1986, Watson et al. 1989, Newton et al. 1994, Westergaard et al. 1995, Quaedvlieg et al. 2001). There was only one study conducted outside of the USA and Europe that qualified for this review, originating in Japan (Ito et al. 2010).

\section{Overall GEP-NET incidence}

Although several registries published data on the IRs of all-site NETs, they were not included in this review as they published data on those of tumours of non-GEP sites (mainly lung) and were not solely dedicated to GEP-NETs.

In the USA, the incidence of GEP-NETs has increased steadily over the past four decades. In the most recent epidemiological study, 29664 patients with GEP-NETs were identified from the SEER database from 1973 to 2007. Between 1973 and 1977, the age-adjusted IR for all GEPNETs was 1.00, increasing to 3.65 between 2003 and 2007 (Lawrence et al. 2011). In the UK, the IR of GI-NETs (excluding pancreatic NETs) increased by 4.8 times in males and 3.8 times in females from the 1970s to the years between 2000 and 2006 (from 0.27 to 1.32 in males

Published by Bioscientifica Ltd 
and from 0.35 to 1.33 in females) (Ellis et al. 2010). The absolute rate of GEP-NETs in the UK was significantly lower than that in the USA over similar time periods. While possibly being explained by true variations in incidence, influenced by local genetic and environmental conditions, these discrepancies mainly raise major concerns on the validity of the method of patient identification used in the different registries and in the same registry over time.

\section{Gastric NETs}

The IRs of gastric NETs are particularly difficult to assess as registries do not differentiate among type I, II and III gastric NETs. Moreover, the registration of these tumours in different cancer registries is variable, with some only documenting malignant tumours while others documenting benign and malignant tumours. In the SEER database up to 1986, only malignant gastric NETs were registered. The differentiation between benign and malignant gastric NETs is not acceptable any more, as all types have various grades of malignant potential (Klimstra et al. 2010a).

In the 1970s, incidence was low: 0.01 in both the USA and the UK (Maggard et al. 2004, Ellis et al. 2010; for details, see Supplementary appendix Table 1 , see section on supplementary data given at the end of this article).

Most recently, the highest IRs of gastric NETs have been reported in the USA (Lawrence et al. 2011) and somewhat lower IRs in Norway (Hauso et al. 2008), the UK (Ellis et al. 2010) and Austria (Niederle et al. 2010; Fig. 2A).

There has been an increase in IRs over time in the UK, the USA, Switzerland and Norway (Levi et al. 2000, Hauso et al. 2008, Yao et al. 2008, Ellis et al. 2010, Lawrence et al. 2011). The most dramatic increases were reported in the UK (15-fold) and in the USA (11-fold) (Modlin \& Sandor 1997, Modlin et al. 1997, 2003, 2004, Maggard et al. 2004, Hodgson et al. 2005, Yao et al. 2008, Ellis et al. 2010, Lawrence et al. 2011). It remains unclear whether this represents a true increase in incidence or reflects increased awareness, changes in method of registration ('malignant' vs 'benign' and 'malignant' tumours) and mainly the increase in the availability and usage of upper endoscopy.

In the USA, there was initially a suggestion that female gender could be protective (Modlin et al. 2004); however, this no longer holds true, as the IRs of gastric NETs now tend to be similar in males and females (Yao et al. 2008). In the USA, over the past 30 years, gastric carcinoids have consistently been more common in Blacks than in Whites (Modlin \& Sandor 1997, Modlin et al. 1997, 2003, 2004, Crocetti \& Paci 2003, Lawrence et al. 2011).

\section{Small intestine-NETs}

In older classification systems, duodenal tumours were classified as foregut carcinoids. In most recent classifications, NETs of the duodenum are considered a distinct entity (Klimstra et al. 2010a, Klöppel 2011).

Despite this, many of the reports summarized in this review included tumours of the duodenum with and without those of the jejunum/ileum as a group of small intestine-NETs (SI-NETs), while others included those arising in all the three sites together.

SI-NETs have been the most common GEP-NETs in the Western world for many years (Ellis et al. 2010, Lawrence et al. 2011), and only recently have they been surpassed by rectal NETs in the USA (Lawrence et al. 2011).

In the 1970s, the lowest IR was recorded in the UK (0.11-0.12) (Ellis et al. 2010). During the same period, IRs in the USA were higher, ranging from 0.28 to 0.82 (lowest in White females and highest in Black males) (Godwin 1975, Maggard et al. 2004, Gustafsson et al. 2008; for details, see Supplementary appendix Table 2, see section on supplementary data given at the end of this article).

Data from different time periods indicate a clear increase in the IRs of SI-NETs over time. Between 1971 and 2006, the increase in IR in the UK was $\sim 3.8$-fold in men and 2.9-fold in women (Ellis et al. 2010), and in the latest report from the SEER database, a 2.8-fold increase has been demonstrated comparing the IR recorded in the early 1970s with that recorded in the mid-2000s (Bilimoria et al. 2009, Lawrence et al. 2011). Smaller increases with different trends in males and females were observed in Sweden (Hemminki \& Li 2001, Landerholm et al. 2010), Burgundy, France (Lepage et al. 2004), Vaud, Switzerland (Levi et al. 2000), and Norway (Hauso et al. 2008). While the increase in the IRs of 'incidental' tumours due to increased imaging and awareness can explain the increase in those of other GEP-NETs, this is less relevant to SI-NETs, which are usually not amenable to luminal imaging with endoscopic techniques.

In recent years, significantly higher IRs have been recorded (Fig. 2B).The highest IR of SI-NETs has been reported in the USA with similarly high IRs being reported over similar time frames in Norway and Jonkoping County, Sweden (Hauso et al. 2008, Landerholm et al. 2010, Lawrence et al. 2011). Lower IRs have been recorded in the latest reports from the UK (Ellis et al. 2010) and Austria (Niederle et al. 2010; see Fig. 2B).

Of note is that this more than twofold variation in the IR of SI-NETs in the USA compared with that in the UK and some other western European countries (see Fig. 2B) raises

Published by Bioscientifica Ltd 


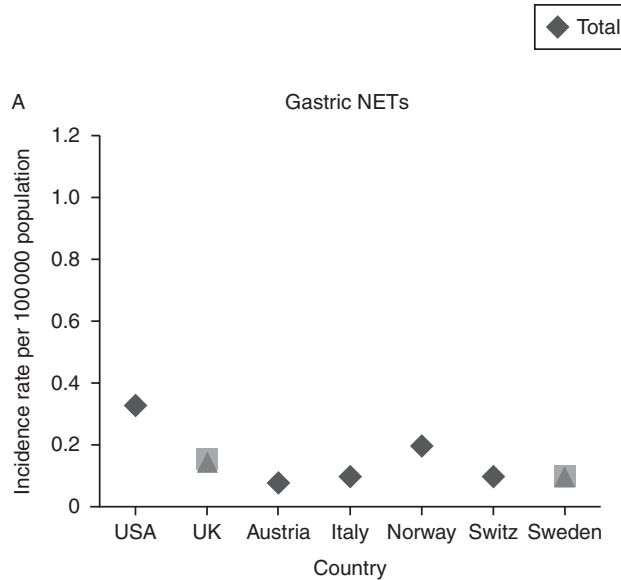

Males $\Delta$ Females
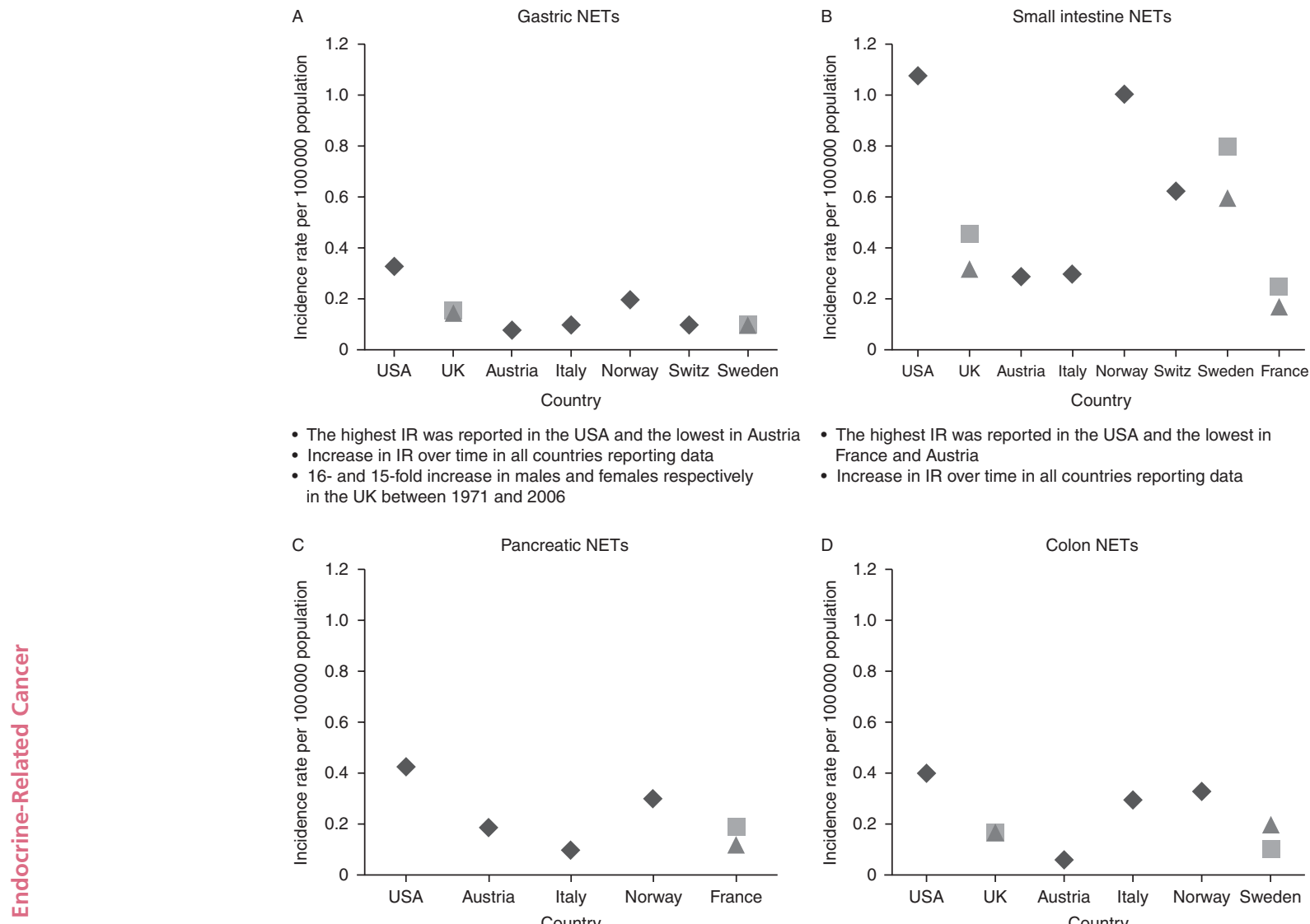

- The highest IR was reported in the USA and the lowest in Austria - The highest IR was reported in the USA and the lowest in - Increase in IR over time in all countries reporting data

- 16- and 15-fold increase in males and females respectively France and Austria

in the UK between 1971 and 2006

- Increase in IR over time in all countries reporting data
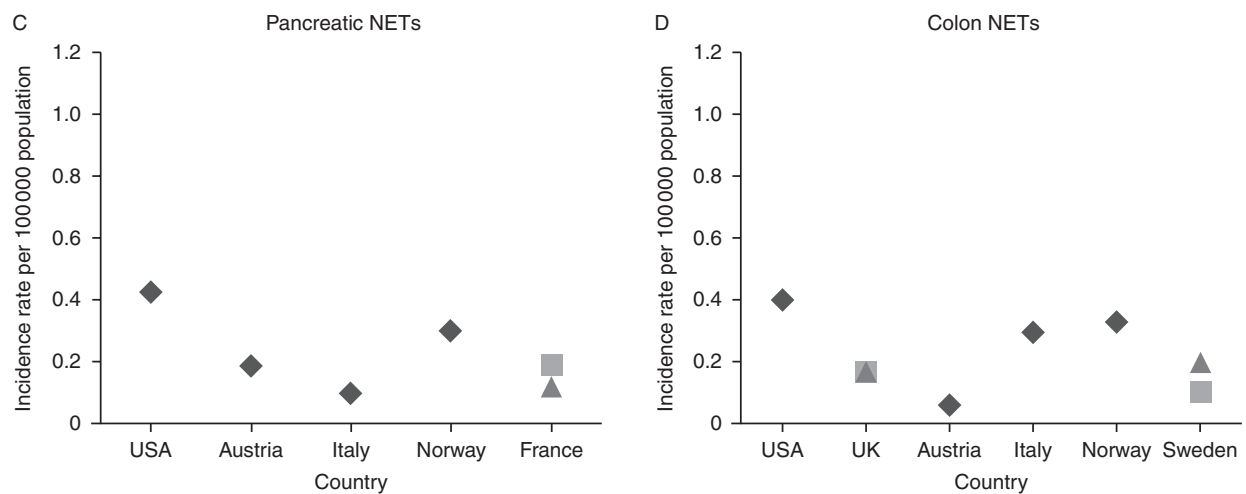

- Little data on IR of pancreatic NETs in Europe - In general, IRs reported in the USA seemed to be higher than those reported in Europe

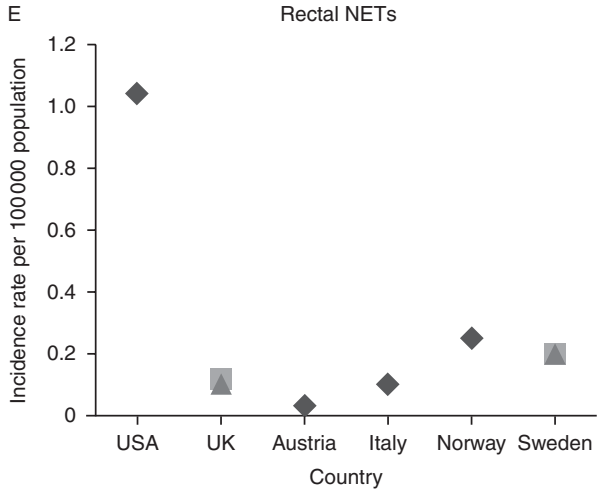

- The highest IR was reported in the USA and the lowest in Aust - In the UK and the USA, IRs increased approximately tenfold between the 1970s and the 2000 s

- Within the colon, there was a predominance of right-sided NETs - Over time, there has been an increase in the IR in the UK, the USA and Norway

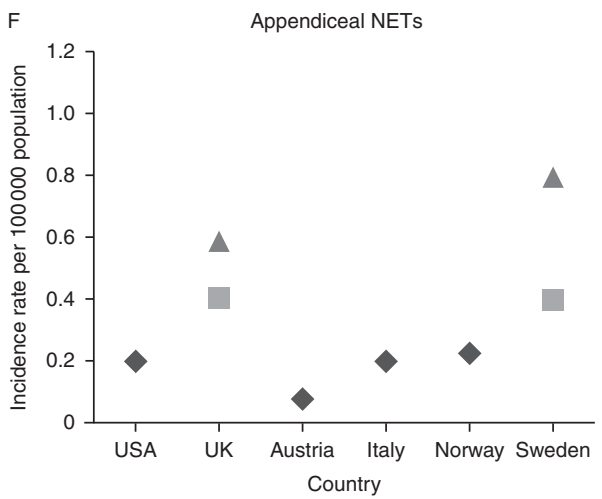

- Difficult to ascertain patterns due to different coding of appendiceal NETs over time and across the countries - The highest IRs were reported in Sweden and the UK and the lowest in Austria

Figure 2

Most recent incidence rates in various countries for six types of NET: (A) gastric, (B) small intestine, (C) pancreatic, (D) colon, (E) rectal, and (F) appendiceal NETs. Data for the various countries are from the following time periods: USA, 2003-2007 (Lawrence et al. 2011); UK, 2000-2006
(Ellis et al. 2010); Austria, 2004-2005 (Niederle et al. 2010); Italy (Tuscany), 1985-2005 (Caldarella et al. 2011); Norway, 2000-2004 (Hauso et al. 2008); Switzerland (Vaud), 1986-1997 (Levi et al. 2000); Sweden, 1983-1998 (Hemminki \& Li 2001); France (Burgundy), 1989-2001 (Lepage et al. 2006).

Published by Bioscientifica Ltd 
some major concerns as to the validity of the various registries and reflects the variation in the methods of patient identification in each country.

In the US SEER registry, jejunal/ileal NETs were the most common among SI-NETs (Yao et al. 2008, Lawrence et al. 2011), and they are more common in African Americans than in Whites (for details, see Supplementary appendix Table 2; Godwin 1975, Chow et al. 1996, Severson et al. 1996, Modlin \& Sandor 1997, Modlin et al. 2003, Yao et al. 2008, Modlin et al. 2004). Male predominance has been reported in most of the countries reporting the IRs of SI-NETs.

\section{Pancreatic NETs}

The most recently reported IRs of pancreatic NETs are shown in Fig. 2C (and in more detail in Supplementary appendix Table 3 , see section on supplementary data given at the end of this article).

In Europe, few reports on the incidence of pancreatic NETs fulfilled our selection criteria. In the USA, the IR of pancreatic NETs has increased with time as apparent from several reports (Modlin et al. 2003, Halfdanarson et al. 2008, Hauso et al. 2008), with the most recent one showing an increase from 0.17 in 1973-1977 to 0.43 in 2003-2007 (Lawrence et al. 2011). Surprisingly, there were major differences in IRs in the different reports based on the SEER database, which may be explained by differences in the ICD code selection. For example, Yao et al. (2007), specifically evaluating the IR of islet cell carcinoma, found a decrease in IR with time between 1973 and 2003. In Norway, the IR of pancreatic NETs doubled from 0.15 to 0.3 between the mid1990s and the early 2000s (Hauso et al. 2008).

In general, IRs in the USA seem to be slightly higher than those in Europe, with a male predominance in France, the USA and Norway, but a female predominance in Italy. In the US SEER population, pancreatic NETs were more common in Whites and African Americans ( 0.32 and 0.36 respectively) than in Asian Americans and American Indians (0.25 and 0.20 respectively) (Yao et al. 2008).

\section{Colorectal NETs}

The incidence of NETs of the colorectum was difficult to assess, as registries variably reported the IRs of colorectal, colon and rectal NETs either together or separately. In addition, some reports included appendiceal NETs (ANETs) with colorectal NETs. Comparisons between geographical areas were especially challenging because of these differences in classification. The incidence of colorectal NETs has increased over the last 40 years. It remains unclear whether this reflects a true increase in incidence or increased availability and usage of flexible sigmoidoscopy and colonoscopy.

Colon NETs The most recently reported IRs of colon NETs are shown in Fig. 2D (for more details, see Supplementary appendix Table 4, see section on supplementary data given at the end of this article). Generally, there was predominance of right-sided NETs in the colon (Ballantyne et al. 1992, Crocetti \& Paci 2003, Modlin et al. 2003, Yao et al. 2008, Ellis et al. 2010, Lawrence et al. 2011).

In the 1970s, the IRs of colon NETs in the UK were as low as 0.05 (Ellis et al. 2010). From the 1970s to the mid2000s, IRs increased approximately fourfold in the UK and more than doubled in the US SEER population (Modlin \& Sandor 1997, Modlin et al. 2003, Maggard et al. 2004, Gustafsson et al. 2008, Hauso et al. 2008, Ellis et al. 2010, Lawrence et al. 2011). Smaller increases in IR have been observed in Norway (Hauso et al. 2008). Interestingly, a recent report from Austria has demonstrated a particularly low IR of 0.06 for colon NETs in the mid-2000s (Niederle et al. 2010).

Racial and gender differences in IRs have also been demonstrated. The IRs of colon NETs remained highest in African Americans (0.38), with lower IRs being observed in American Indians (0.22) and Whites (0.18) and the lowest IR in Asians (0.12) (Yao et al. 2008). With respect to gender, the IRs of colon NETs were higher in males in the USA (Godwin 1975, Hauso et al. 2008, Yao et al. 2008), but the opposite was true in Italy, Norway and Sweden (Hemminki \& Li 2001, Hauso et al. 2008, Caldarella et al. 2011).

Rectal NETs The most recently reported IRs of rectal NETs are shown in Fig. 2E (for more details, see Supplementary appendix Table 5 , see section on supplementary data given at the end of this article). In the early 1970s, the IRs for rectal NETs were ten times lower in the UK than in the USA ( 0.01 and 0.1 per 100000 respectively) (Godwin 1975, Modlin \& Sandor 1997, Modlin et al. 2003, Ellis et al. 2010, Lawrence et al. 2011). From the 1970s to the mid-2000s, IRs increased approximately tenfold in both the countries, reaching a maximum of only 0.12 in the UK when compared with 1.05 in the US SEER population (Ellis et al. 2010, Lawrence et al. 2011). The lowest IR of rectal NETs has been reported in Austria, which was 0.03 in the mid-2000s (Niederle et al. 2010). Modest increases in the IRs of rectal NET have been reported from other European countries such as Norway (Hauso et al. 2008).

Published by Bioscientifica Ltd. 
Racial and gender differences in the incidence of rectal NETs have been reported. In the USA, racial differences in the incidence of rectal NETs have been demonstrated, with the highest frequency in African Americans (1.80), followed by that in Asian Americans (1.25) and American Indians (1.0), and the lowest frequency in Whites (0.66) (Godwin 1975, Modlin \& Sandor 1997, Modlin et al. 2003, Yao et al. 2008). In the UK and Norway, the IRs of rectal NETs were only slightly higher in males than in females, and there were no gender differences in Italy and Sweden (Hemminki \& Li 2001, Hauso et al. 2008, Ellis et al. 2010, Caldarella et al. 2011).

\section{Appendiceal NETs}

The most recently reported IRs of ANETs are shown in Fig. 2F (for more details, see Supplementary appendix Table 6 , see section on supplementary data given at the end of this article).

The registration of ANETs has changed over time, depending on whether only malignant tumours or both benign and malignant tumours were included.

In the 1970s, the lowest IRs were recorded in the UK and were 0.03 in males and 0.05 in females (21, Ellis). During the same period, IRs in the USA were slightly higher at 0.07-0.12 (Godwin 1975, Modlin \& Sandor 1997, Modlin et al. 2003, Maggard et al. 2004, Gustafsson et al. 2008, Lawrence et al. 2011).

The IR of ANETs has increased over time in all the countries. Interpreting this increase in IR is complex due to the differences in registration mentioned earlier (Hemminki \& Li 2001, Ellis et al. 2010, Caldarella et al. 2011). Another source of error in reporting the incidence of ANETs is the fact that it is often an incidental finding, and removed appendices are sent for pathology with a frequency that may vary between countries and over time.

The most dramatic increase in IR was observed in the UK (tenfold) between 1979 and 2006, largely explained by the change in the International Classification of Disease for Oncology (ICD-O) coding, which from 1995 onwards included both benign and malignant ANETs (Ellis et al. 2010). In Norway and the USA, IRs increased much more mildly (about twofold) over various time periods (Hauso et al. 2008, Lawrence et al. 2011).

In recent years, significantly higher IRs have been recorded: highest in the UK (Ellis et al. 2010) and significantly lower over similar time frames in the USA (Yao et al. 2008, Lawrence et al. 2011), Norway (Hauso et al. 2008) and Austria (Niederle et al. 2010; see Fig. 2F).
The IRs of ANETs are higher in females than in males in all countries reporting incidence by gender, and as of the 1990s, ANETs are the most common GI-NETs in women in the UK (Ellis et al. 2010). In the US SEER registry, the IRs of ANETs are several fold higher in Whites and African Americans than in Asian Americans and American Indians (see Supplementary appendix Table 6; Yao et al. 2008).

\section{Data from Japan}

The study carried out by Ito et al. (see Supplementary appendix Table 7 , see section on supplementary data given at the end of this article), reporting on the incidence of GEP-NETs in Japan, is unique in several aspects. It is one of the few reporting on the prevalence as opposed to just incidence. The calculation of IRs was not done by identifying patients according to the ICD-O codes in cancer registries. Rather, a nationwide survey of GEP-NET patients in Japan who received treatment from 1 January to 31 December 2005 was conducted in a sample of hospitals and departments that were chosen using stratified random sampling. This study differs from all other studies included in this review, in that it used the old classification of NETs: foregut, midgut and hindgut. For these reasons, it is difficult to make comparisons between IRs from Japan and other parts of the world (Ito et al. 2010).

\section{Discussion}

By reviewing all the published articles concerning the epidemiology of GEP-NETs, we found that 33 were population-based studies providing information on the incidence of these tumours per year. Our findings are briefly summarized below.

\section{Data source}

The IRs of GEP-NETs are available from national and regional cancer registries in North America, Western Europe and Japan, but not from other parts of the world.

Most of the published data on the epidemiology of NETs are based on small and heterogeneous series, where the real incidence of these tumours for most sites is not completely known and probably not reliably estimated. In this review, we included only publications that strictly fulfilled our inclusion criteria to present only true IRs, at the national or regional level. Table 1 presents the heterogeneity of data sources and means of registration

Published by Bioscientifica Ltd 
used by the different studies included in this review and thus explains why pooling of data in the form of a metaanalysis was not possible. This may also explain part of the differences observed in the IRs of GEP-NETs between the USA and Europe, which to our opinion cannot be completely attributed to a true variation in IRs.

Major changes have been made in the classification of NETs from their original identification by Oberndorfer in the early 1900s, who coined the term 'karzinoid' (Oberndorfer 1907). Inconsistency in the nomenclature and classification of NETs is the major limitation to the elucidation of the precise epidemiology of GEP-NETs. This is reflected in the ICD-O coding system that used one of several names to describe the same tumour: apudoma/ carcinoid tumour/enterchromaffin cell carcinoid and so on (Lawrence et al. 2011). Another source of error as to the true incidence of GEP-NETs is that older cancer registries included only 'malignant carcinoids' while not including 'benign' tumours. At the same time, other registries reported both 'benign' and 'malignant' tumours. This has changed, with the new ICD-O 10 coding already including 'benign' NETs, and may explain some of the increase in the incidence of GEP-NETs being reported around the world. Furthermore, the current NET classification (WHO and ENETS) does not discriminate between benign and malignant NETs; rather, the classification relies on histological grade and differentiation, rendering all NETs as neoplasms with a degree of malignant potential (Klöppel et al. 2009, Klimstra et al. 2010a,b).

\section{Trends in IRs}

The age-adjusted incidence of all GEP-NETs has steadily increased in the last four decades, increasing in the time interval $1973-2007$ by 3.6 -fold in the USA and by 3.8- to 4.8-fold in Europe. The small intestine (SI) and rectum are currently the most common primary sites for GEP-NETs.

The highest increase in IR in recent years/decades has been observed for gastric and rectal NETs, whereas the IRs of SI-NETs have changed least among the various sites/locations.

There are gender and racial differences, which differ site by site and, in some cases, change over time and are different between countries and continents.

\section{Limitations of the available data}

Our findings were limited by the heterogeneity of data reporting and presentation and by the fact that some of the reports were not population based and therefore did not report annual IRs, with very little data on prevalence rates. Heterogeneity was apparent in several aspects including different countries and study populations; different methods of patient identification (see Table 1); different time intervals during which incidence data were calculated; variations in the way data were presented (age, gender and race); site of origin of the tumour; and grade of malignancy. Only one study used the $2000 \mathrm{WHO}$ classification (Austria), and no studies used the 2010 WHO classification. Most reports had a retrospective study design with only one prospective study (Austria) in which IRs were established taking into account all diagnoses of NETs made in that country in 1 year. Multiple reports for the same population, e.g. the numerous SEER-based publications, were not always consistent with each other. As of the second decade of the twenty-first century, data on the IRs of GEP-NETs are still lacking in many parts of the world, including the Far East and Africa.

The assessment of trends in the IRs of GEP-NETs is confounded by multiple factors. The classification of GEPNETs has changed with time. Benign tumours were not included in some of the older studies, while today we know that all NETs have a malignant potential. In addition, the increased awareness of NETs in clinicians and pathologists and the use of NET classifications in more recent years might at least partly explain the increase in the incidence of NETs being reported. Both awareness of NETs by clinicians and pathologists and increase in the clinical use of luminal and anatomical imaging have probably contributed significantly to the increase in the IRs of GEP-NETs being reported, while the precise contribution of the true increase is hard to assess. It is our opinion, based on the existing data, that it is impossible to draw conclusions as to the true trends in the IRs of GEP-NETs around the world.

\section{The future}

Future studies in the field of GEP-NET epidemiology should aim to report annual age-adjusted IRs and prevalence rates. Population-based studies, ideally of whole countries, identifying all NET cases on the basis of standardized collection of pathology reports, using a uniform classification system, preferably based on the most updated WHO classification, should be carried out to assess the possible topographical differences and changes in incidence with time. These studies should be conducted in different parts of the world. Overall, this information may promote our understanding of the genetic and

Published by Bioscientifica Ltd. 
environmental factors that contribute to the development of GEP-NETs in different parts of the world.

\section{Supplementary data}

This is linked to the online version of the paper at http://dx.doi.org/10.1530/ ERC-13-0125.

\section{Declaration of interest}

M F, M K, A F and G D V have no conflicts of interest to declare. W D H has been on advisory boards organized by Novartis and Ipsen.

\section{Funding}

This article was developed independently by members of a working group of the Knowledge Network. This programme involved meetings and collaboration between clinicians working in the field of NETs around the world, which was organized and funded by Ipsen. The authors are fully responsible for the concept and all the content, for all the editorial decisions, and for the approval of the final version.

\section{Author contribution statement}

All authors screened the search results and compiled datasheets with IRs of the study population and wrote the manuscript and reviewed the final version.

\section{Acknowledgements}

The authors thank the participants of the Knowledge Network. They also thank Alex Coulthard of Echo Communications, UK, for editorial assistance, funded by Ipsen, in the preparation of this manuscript.

\section{References}

Ballantyne GH, Savoca PE, Flannery JT, Ahlman MH \& Modlin IM 1992 Incidence and mortality of carcinoids of the colon. Data from the Connecticut Tumor Registry. Cancer 69 2400-2405. (doi:10.1002/10970142(19920515)69:10<2400::AID-CNCR2820691003>3.0.CO;2-Z)

Berge T \& Linell F 1976 Carcinoid tumours. Frequency in a defined population during a 12-year period. Acta Pathologica, Microbiologica, et Immunologica Scandinavica 84 322-330.

Bilimoria KY, Bentrem DJ, Wayne JD, Ko CY, Bennett CL \& Talamonti MS 2009 Small bowel cancer in the United States: changes in epidemiology, treatment, and survival over the last 20 years. Annals of Surgery 249 63-71. (doi:10.1097/SLA.0b013e31818e4641)

Buchanan KD, Johnston CF, O'Hare MM, Ardill JE, Shaw C, Collins JS, Watson RG, Atkinson AB, Hadden DR, Kennedy TL et al. 1986 Neuroendocrine tumors. A European view. American Journal of Medicine 81 14-22. (doi:10.1016/0002-9343(86)90581-4)

Caldarella A, Crocetti E \& Paci E 2011 Distribution, incidence, and prognosis in neuroendocrine tumors: a population based study from a cancer registry. Pathology Oncology Research 17 759-763. (doi:10.1007/ s12253-011-9382-y)

Chow JS, Chen CC, Ahsan H \& Neugut AI 1996 A population-based study of the incidence of malignant small bowel tumours: SEER, 1973-1990. International Journal of Epidemiology 25 722-728. (doi:10.1093/ije/25. 4.722)

http://erc.endocrinology-journals.org DOI: 10.1530/ERC-13-0125
(C) 2014 Society for Endocrinology Printed in Great Britain
Crocetti E \& Paci E 2003 Malignant carcinoids in the USA, SEER 1992-1999. An epidemiological study with 6830 cases. European Journal of Cancer Prevention 12 191-194. (doi:10.1097/00008469-20030600000004)

Crocetti E, Buiatti E \& Amorosi A 1997 Epidemiology of carcinoid tumours in central Italy. European Journal of Epidemiology 13 357-359. (doi:10.1023/A:1007334217762)

Ellis L, Shale MJ \& Coleman MP 2010 Carcinoid tumors of the gastrointestinal tract: trends in incidence in England since 1971. American Journal of Gastroenterology 105 2563-2569. (doi:10.1038/ajg. 2010.341)

Garcia-Carbonero R, Capdevila J, Crespo-Herrero G, Díaz-Pérez JA, Martínez Del Prado MP, Alonso Orduña V, Sevilla-García I, VillabonaArtero C, Beguiristain-Gómez A, Llanos-Muñoz M et al. 2010 Incidence, patterns of care and prognostic factors for outcome of gastroenteropancreatic neuroendocrine tumors (GEP-NETs): results from the National Cancer Registry of Spain (RGETNE). Annals of Oncology 21 1794-1803. (doi:10.1093/annonc/mdq022)

Godwin JD II 1975 Carcinoid tumors. An analysis of 2,837 cases. Cancer 36 560-569. (doi:10.1002/1097-0142(197508)36:2<560::AIDCNCR2820360235>3.0.CO;2-4)

Gustafsson BI, Siddique L, Chan A, Dong M, Drozdov I, Kidd M \& Modlin IM 2008 Uncommon cancers of the small intestine, appendix and colon: an analysis of SEER 1973-2004, and current diagnosis and therapy. International Journal of Oncology 33 1121-1131.

Halfdanarson TR, Rabe KG, Rubin J \& Petersen GM 2008 Pancreatic neuroendocrine tumors (PNETs): incidence, prognosis and recent trend toward improved survival. Annals of Oncology 19 1727-1733. (doi:10.1093/annonc/mdn351)

Hauso O, Gustafsson BI, Kidd M, Waldum HL, Drozdov I, Chan AK \& Modlin IM 2008 Neuroendocrine tumor epidemiology: contrasting Norway and North America. Cancer 113 2655-2664. (doi:10.1002/cncr. 23883)

Hemminki K \& Li X 2001 Incidence trends and risk factors of carcinoid tumors: a nationwide epidemiologic study from Sweden. Cancer 92 2204-2210. (doi:10.1002/1097-0142(20011015)92:8<2204::AIDCNCR1564>3.0.CO;2-R)

Hodgson N, Koniaris LG, Livingstone AS \& Franceschi D 2005 Gastric carcinoids: a temporal increase with proton pump introduction. Surgical Endoscopy 19 1610-1612. (doi:10.1007/s00464-005-0232-4)

Ito T, Sasano H, Tanaka M, Osamura RY, Sasaki I, Kimura W, Takano K, Obara T, Ishibashi M, Nakao K et al. 2010 Epidemiological study of gastroenteropancreatic neuroendocrine tumors in Japan. Journal of Gastroenterology 45 234-243. (doi:10.1007/s00535-009-0194-8)

Klimstra DS, Modlin IR, Adsay NV, Chetty R, Deshpande V, Gönen M, Jensen RT, Kidd M, Kulke MH, Lloyd RV et al. 2010a Pathology reporting of neuroendocrine tumors: application of the Delphic consensus process to the development of a minimum pathology data set. American Journal of Surgical Pathology 34 300-313. (doi:10.1097/PAS. Ob013e3181ce1447)

Klimstra DS, Modlin IR, Coppola D, Lloyd RV \& Suster S $2010 b$ The pathologic classification of neuroendocrine tumors: a review of nomenclature, grading, and staging systems. Pancreas 39 707-712. (doi:10.1097/MPA.0b013e3181ec124e)

Klöppel G 2011 Classification and pathology of gastroenteropancreatic neuroendocrine neoplasms. Endocrine-Related Cancer 18 (Suppl 1) S1-S16. (doi:10.1530/ERC-11-0013)

Klöppel G, Couvelard A, Perren A, Komminoth P, McNicol AM, Nilsson O, Scarpa A, Scoazec JY, Wiedenmann B, Papotti M et al. 2009 ENETS Consensus Guidelines for the Standards of Care in Neuroendocrine Tumors: towards a standardized approach to the diagnosis of gastroenteropancreatic neuroendocrine tumors and their prognostic stratification. Neuroendocrinology 90 162-166. (doi:10.1159/000182196)

Klöppel G, Rindi G, Perren A, Komminoth P \& Klimstra DS 2010 The ENETS and AJCC/UICC TNM classifications of the neuroendocrine tumors of

Published by Bioscientifica Lto. 
the gastrointestinal tract and the pancreas: a statement. Virchows Archiv 456 595-597. (doi:10.1007/s00428-010-0924-6)

Kwekkeboom DJ, Krenning EP, Lebtahi R, Komminoth P, Kos-Kudła B, de Herder WW, Plöckinger U \& Mallorca Consensus Conference participants; European Neuroendocrine Tumor Society 2009 ENETS Consensus Guidelines for the Standards of Care in Neuroendocrine Tumors: peptide receptor radionuclide therapy with radiolabeled somatostatin analogs. Neuroendocrinology 90 220-226. (doi:10.1159/ 000225951)

Landerholm K, Falkmer S \& Järhult J 2010 Epidemiology of small bowel carcinoids in a defined population. World Journal of Surgery 34 1500-1505. (doi:10.1007/s00268-010-0519-z)

Lawrence B, Gustafsson BI, Chan A, Svejda B, Kidd M \& Modlin IM 2011 The epidemiology of gastroenteropancreatic neuroendocrine tumors. Endocrinology and Metabolism Clinics of North America 40 1-18. (doi:10.1016/j.ecl.2010.12.005)

Lepage C, Bouvier AM, Phelip JM, Hatem C, Vernet C \& Faivre J 2004 Incidence and management of malignant digestive endocrine tumours in a well defined French population. Gut 53 549-553. (doi:10.1136/gut. 2003.026401)

Lepage C, Bouvier AM, Manfredi S, Dancourt V \& Faivre J 2006 Incidence and management of primary malignant small bowel cancers: a welldefined French population study. American Journal of Gastroenterology 101 2826-2832. (doi:10.1111/j.1572-0241.2006.00854.x)

Levi F, Randimbison L, Franceschi S \& La Vecchia C 1993 Descriptive epidemiology of malignant carcinoids in the Swiss Canton of Vaud. International Journal of Cancer 53 1036-1037. (doi:10.1002/ijc. 2910530630)

Levi F, Te VC, Randimbison L, Rindi G \& La Vecchia C 2000 Epidemiology of carcinoid neoplasms in Vaud, Switzerland, 1974-97. British Journal of Cancer 83 952-955. (doi:10.1054/bjoc.2000.1394)

Li AF, Hsu CY, Li A, Tai LC, Liang WY, Li WY, Tsay SH \& Chen JY 2008 A 35-year retrospective study of carcinoid tumors in Taiwan: differences in distribution with a high probability of associated second primary malignancies. Cancer 112 274-283. (doi:10.1002/cncr.23159)

Lombard-Bohas C, Mitry E, O'Toole D, Louvet C, Pillon D, Cadiot G, Borson-Chazot F, Aparicio T, Ducreux M, Lecomte T et al. 2009 Thirteen-month registration of patients with gastroenteropancreatic endocrine tumours in France. Neuroendocrinology 89 217-222. (doi:10.1159/000151562)

Maggard MA, O'Connell JB \& Ko CY 2004 Updated population-based review of carcinoid tumors. Annals of Surgery 240 117-122. (doi:10.1097/01.sla.0000129342.67174.67)

Modlin IM \& Sandor A 1997 An analysis of 8305 cases of carcinoid tumors. Cancer 79 813-829. (doi:10.1002/(SICI)1097-0142(19970215)79:4 $<813:$ :AID-CNCR19>3.0.CO;2-2)

Modlin IM, Sandor A, Tang LH, Kidd M \& Zelterman D 1997 A 40-year analysis of 265 gastric carcinoids. American Journal of Gastroenterology 92 633-638.

Modlin IM, Lye KD \& Kidd M 2003 A 5-decade analysis of 13,715 carcinoid tumors. Cancer 97 934-959. (doi:10.1002/cncr.11105)

Modlin IM, Lye KD \& Kidd M 2004 A 50-year analysis of 562 gastric carcinoids: small tumor or larger problem? American Journal of Gastroenterology 99 23-32. (doi:10.1046/j.1572-0241.2003.04027.x)
Modlin IM, Champaneria MC, Chan AK \& Kidd M 2007 A three-decade analysis of 3,911 small intestinal neuroendocrine tumors: the rapid pace of no progress. American Journal of Gastroenterology $\mathbf{1 0 2}$ 1464-1473. (doi:10.1111/j.1572-0241.2007.01185.x)

Newton JN, Swerdlow AJ, dos Santos Silva IM, Vessey MP, Grahame-Smith DG, Primatesta P \& Reynolds DJ 1994 The epidemiology of carcinoid tumours in England and Scotland. British Journal of Cancer 70 939-942. (doi:10.1038/bjc.1994.424)

Niederle MB, Hackl M, Kaserer K \& Niederle B 2010 Gastroenteropancreatic neuroendocrine tumours: the current incidence and staging based on the WHO and European Neuroendocrine Tumour Society classification: an analysis based on prospectively collected parameters. EndocrineRelated Cancer 17 909-918. (doi:10.1677/ERC-10-0152)

Oberndorfer S 1907 Karzinoide tumoren des dünndarms. Frankfurter Zeitschrift för Pathologie 1 426-432.

Ploeckinger U, Kloeppel G, Wiedenmann B, Lohmann R \& representatives of 21 German NET Centers 2009 The German NETregistry: an audit on the diagnosis and therapy of neuroendocrine tumors. Neuroendocrinology 90 349-363. (doi:10.1159/000242109)

Quaedvlieg PF, Visser O, Lamers CB, Janssen-Heijen ML \& Taal BG 2001 Epidemiology and survival in patients with carcinoid disease in The Netherlands. An epidemiological study with 2391 patients. Annals of Oncology 12 1295-1300. (doi:10.1023/A:1012272314550)

Severson RK, Schenk M, Gurney JG, Weiss LK \& Demers RY 1996 Increasing incidence of adenocarcinomas and carcinoid tumors of the small intestine in adults. Cancer Epidemiology, Biomarkers \& Prevention 5 81-84.

Sundin A, Vullierme MP, Kaltsas G, Plöckinger U \& Mallorca Consensus Conference participants; European Neuroendocrine Tumor Society 2009 ENETS Consensus Guidelines for the Standards of Care in Neuroendocrine Tumors: radiological examinations. Neuroendocrinology 90 167-183. (doi:10.1159/000184855)

Watson RG, Johnston CF, O'Hare MM, Anderson JR, Wilson BG, Collins JS, Sloan JM \& Buchanan KD 1989 The frequency of gastrointestinal endocrine tumours in a well-defined population - Northern Ireland 1970-1985. Quarterly Journal of Medicine 72 647-657.

Westergaard T, Frisch M \& Melbye M 1995 Carcinoid tumors in Denmark 1978-1989 and the risk of subsequent cancers. A population-based study. Cancer 76 106-109. (doi:10.1002/1097-0142(19950701)76:1 $<106:$ :AID-CNCR2820760116>3.0.CO;2-W)

Yao JC, Eisner MP, Leary C, Dagohoy C, Phan A, Rashid A, Hassan M \& Evans DB 2007 Population-based study of islet cell carcinoma. Annals of Surgical Oncology 14 3492-3500. (doi:10.1245/s10434-0079566-6)

Yao JC, Hassan M, Phan A, Dagohoy C, Leary C, Mares JE, Abdalla EK, Fleming JB, Vauthey JN, Rashid A et al. 2008 One hundred years after 'carcinoid': epidemiology of and prognostic factors for neuroendocrine tumors in 35,825 cases in the United States. Journal of Clinical Oncology 26 3063-3072. (doi:10.1200/JCO.2007.15.4377)

Younes RN \& GETNE (Grupo de Estudo de Tumores Neuroendócrinos) 2008 Neuroendocrine tumors: a registry of 1,000 patients. Revista da Associação Médica Brasileira 54 305-307. (doi:10.1590/S010442302008000400014)

Received in final form 6 December 2013

Accepted 9 December 2013

Made available online as an Accepted Preprint

9 December 2013 http://erc.endocrinology-journals.org DOI: 10.1530/ERC-13-0125
(C) 2014 Society for Endocrinology Printed in Great Britain 